\title{
Assessment of Electrocardiogram Indices in Postmenopausal Women: Effects of Aerobic Exercise and Detraining
}

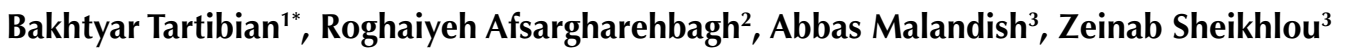 \\ 'Department of Sport Injuries and Corrective Exercise, Faculty of Physical Education and Sport Sciences, Head of Core \\ Research of Health Physiology \& Physical Activity, Allameh Tabataba'i University, Tehran, Iran \\ ${ }^{2}$ Department of Cardiology, Shohada Hospital, Urmia University of Medical Sciences, Urmia, Iran \\ ${ }^{3}$ Department of Exercise Physiology, Urmia University, Urmia, Iran
}

\section{*Correspondence to \\ Bakhtyar Tartibian, Department of Sport Sciences and the corrective movements, Faculty of Physical Education and Sport Sciences, Allameh Tabataba'i University, Tehran, Iran. \\ Tel: +989126090551 Email: ba.tartibian@gmail.com}

Received December 23, 2017 Accepted February 10, 2018

Published online March 31, 2018

Please cite this article as follows: Tartibian B, Afsargharehbagh R, Malandish A, Sheikhlou Z. Assessment of electrocardiogram indices in postmenopausal women: effects of aerobic exercise and detraining. Int J Basic Sci Med. 2018;3(1):3845. doi:10.15171/ ijbms.2018.07.

\begin{abstract}
Introduction: Electrocardiogram (ECG) indices are valuable tools for the diagnosis, depolarization, and repolarization of the myocardium during aerobic exercise and detraining. The purpose of this study was to investigate the effects of 12-week moderate-intensity aerobic exercise and 5 months detraining on ECG indices in post-menopausal women.

Methods: Twenty-four post-menopausal women aged 50-70 years were randomly assigned to exercise $(E, n=12)$ and control $(C, n=12)$ groups. E group performed 12-week moderateintensity aerobic exercise program (W-WJMIAEP-R), and then 5 months detraining remained, but the $C$ group participated in no intervention during the 8 months of the study. The ECG indices were measured at baseline, after 12-week exercise, and after 5-month detraining. Results: After 12 weeks, ECG indices were not significantly different $(P>0.05)$ between the groups, except for $\mathrm{P}-\mathrm{R}$ interval $(P \leq 0.05)$ which was significantly higher in the $\mathrm{E}$ group. After 5 -month detraining, indices were not significantly different between the groups $(P>0.05)$, except for P-R segment and S-T interval $(P \leq 0.05)$ which were significantly decreased in the E group. Conclusion: The results suggested that 12 weeks of walking \& jogging aerobic exercise with $65-70 \%$ maximal heart rate increased the P-R interval. In addition, P-R segment and S-T interval decreased after 5 months of detraining period in sedentary post-menopausal women. Keywords: Aerobic training, Detraining, ECG, Menopause.
\end{abstract}

\section{Introduction}

Cardiovascular diseases in postmenopausal women are known as a global health problem..$^{1-3}$ According to the statistical studies, about 15 million Iranian people suffer from a cardiovascular disease that this rate is 4-times higher than global statistics, especially during menopause. ${ }^{4}$ Due to the cardiovascular disease-induced mortality, identification and diagnosis of abnormal cardiac events at the early stages have attracted the attention of many cardiologists and exercise physiologists. In this regard, electrocardiogram (ECG) provides a valuable tool for the diagnosis of depolarization and repolarization of myocardium and/or the electrical activity of the heart that produced by the ion changes leading to action potentials. ${ }^{5}$

The components of the ECG complex include cardiac waves ( $P$ wave, QRS complex, and $\mathrm{T}$ wave) and cardiac segments \& intervals (P-R segment, ST segment, $\mathrm{Q}-\mathrm{T}$ interval, and P-Rinterval). The cardiac waves indicate both depolarization (contraction) and repolarization (relaxation) of the heart. The cardiac segments and intervals represent either a delay in atrioventricular (AV) node of the impulse or repolarization. ${ }^{6}$ The ECG also provides a very accurate measure of heart rate. ${ }^{6}$ Many factors affect the ECG changes including cardiovascular risk factors and cardiac biomarkers such as various diseases, ${ }^{2}$ aging, ${ }^{2,3}$ aerobic exercise, ${ }^{3}$ physical inactivity, detraining, ${ }^{3}$ and sex hormones $^{7}$ during menopause.

(C) 2018 The Author(s); Published by Zabol University of Medical Sciences. This is an open-access article distributed under the terms of the Creative Commons Attribution License (http://creativecommons.org/licenses/by/4.0), which permits unrestricted use, distribution, and reproduction in any medium, provided the original work is properly cited. 
Since the aging process affects $\mathrm{Ca}^{2+}$ levels by decreasing bone density during menopause which is characterized with reduction of some of the sex hormones such as estrogen and progesterone, resulting in cardiovascular disease with a sedentary lifestyle in post-menopausal women. Recently, we reported that the aging processinduced detraining or physical inactivity increases cardiovascular risk factors including decreased levels of vitamin $\mathrm{D}$ due to a decrease in $\mathrm{Ca}^{2+}$ intestinal absorption and homeostasis, and elevation of blood pressure (BP), ${ }^{2}$ and alternations in ECG indices such as cardiac waves and heart rate. ${ }^{8}$ In contrast, our recent studies showed that the regular aerobic exercise produces phenotypic and genotypic changes and/or anatomical and physiological adaptations in the cardiovascular system, especially the growth of myocyte cells which is considered as a nonpharmacological adaptation against cardiovascular disease. ${ }^{3,9}$ Also, the beneficial effects of aerobic exercise training in lowering BP are observable at the molecular level in prehypertensive post-menopausal women. ${ }^{9}$ In another study, we reported that the aerobic exercise training created a suitable level of fitness, thereby can affect the aging process. ${ }^{3,9,10}$ In other words, moderateintensity aerobic exercise is one of the most effective ways of reducing risk factors for cardiovascular disease and mortality. ${ }^{9,10}$

Thus, the first purpose of this study was to examine the effect of 12 weeks of the protocol; warm up- walking and jogging moderate-intensity aerobic exercise programrecovery (W-WJMIAEP-R) on ECG indices, including heart rate, cardiac waves, and cardiac segments \& intervals in post-menopausal women. The second aim was to examine the effect of five months of detraining on ECG indices in post-menopausal women.

\section{Methods}

Subjects

This study was performed in a randomized control design. This study was conducted in June 2017 at Allameh Tabataba'i University, Iran. The statistical population was all healthy and sedentary post-menopausal women of 5070 years old in Urmia city, Iran. During the public notice of exercise and post-menopausal women, 300 healthy \& sedentary post-menopausal women declared that among them 24 participants qualified for the study.

Inclusion criteria of subjects included (1) postmenopausal women with the age range of 50 to 70 years were spent at least 1 year at menopause, as this was controlled by evaluating the normal menopause serum levels of $17 \beta$-estradiol (11-65 $\mu \mathrm{L} / \mathrm{pg})$ and progesterone (0.1-1 $\mu \mathrm{L} / \mathrm{ng}),(2)$ no history or current diseases affecting cardiovascular system, and (3) no history of regular exercise training for at least 6 months before the start of the study.

Cardiovascular system was evaluated using normal 12lead ECG (Esaote Spa, Firenze, Italy). After obtaining an inform consent, subjects were randomly divided into 2 exercise $(\mathrm{E}, \mathrm{n}=12)$ and control $(\mathrm{C}, \mathrm{n}=12)$ groups.

E group performed 12 weeks walking \& jogging moderate-intensity aerobic exercise with 65\%-70\% maximal heart rate, and then they performed 5 months detraining. The $\mathrm{C}$ group participated in no intervention during 8 months and maintained their normal daily physical activity. Health status and physical activity level of subjects were measured by Health $(\mathrm{H})$ \& Physical Activity Questionnaires (PAQ), respectively. ${ }^{11}$ The data analysis and the assessor who collected the data were blinded to the group allocation.

\section{Sample Size}

Sample size was calculated using $\mathrm{G}^{*}$ Power software ${ }^{12}$ (version 8.0.50727.42; Franz Faul, Universitat Kiel, Dusseldorf, Germany) for repeated measures, withinbetween interaction for detecting an effect size $\mathrm{f}(0.4)$ with $\alpha$ as 0.05 and power of study as 0.95 (95\%), which revealed that 12 participants per group were needed.

\section{Exercise \& Detraining Program}

To determine maximal oxygen uptake of subjects $\left(\mathrm{VO}_{2 \max }\right)$ graded exercise test (GXT) of treadmill by George et al was used. ${ }^{10}$ E group performed 12 weeks walking \& jogging moderate-intensity aerobic exercise with 65\%-70\% maximal heart rate of training on a treadmill, 3 sessions per week and 50-60 minutes per session in the morning. Each training session included 10 minutes warming up, 40 minutes of walking \& jogging aerobic exercise, and 10 minutes cooling down/recovery. The exercises were performed with maximum heart rate $\left(\mathrm{HR}_{\max }\right)$ of $50 \%$ (the first week), 60\% (the next 2 weeks), 65\% (the following 4 weeks), and $70 \%$ (the remaining 5 weeks). ${ }^{10}$ Following the exercises protocol, 5 months of detraining was performed. Control group participated in no intervention and continued their normal lifestyle.

\section{Measurements \\ Blood Sampling and Assays}

The serum levels of $17 \beta$-estradiol and progesterone were measured at baseline (24 hours before initiation of the experiment). Following a 12-hour overnight fast, blood samples $(5 \mathrm{~mL})$ were taken from a brachial vein by Venoject needles in a situation of sit-down \& relaxation. To separate serum, blood samples were centrifuged at a speed of $3000 \mathrm{rpm}$ for 15 minutes at $4^{\circ} \mathrm{C}$ by centrifuge machine. Serum levels of $17 \beta$-estradiol and progesterone were measured using enzyme-linked immunosorbent assay (ELISA) kits; (1561-DRG, Euroimmun, Germany) and (2633-DRG, Euroimmun, Germany), respectively (Stat Fax $^{\circledR} 4200$ - Awareness Technology, USA).

\section{ECG Indices Measurements}

ECG indices measurements, including heart rate, cardiac waves ( $\mathrm{P}$ wave, $\mathrm{QRS}$ complex, and $\mathrm{T}$ wave), and cardiac 
segments \& intervals (P-R segment, ST segment, Q-T interval, and $\mathrm{P}-\mathrm{R}$ interval) were evaluated by 12-lead electrocardiograph (P8000, Esaote, Italy) three times at baseline, 24 hours after the 12 -week exercise intervention, and 24 hours after the 5-month detraining. The number of small squares in two sequential R-R divided by 1500 to calculate heart rate from 12-lead ECG. ${ }^{6}$ The maximum height of cardiac waves ( $\mathrm{P}$ wave, QRS complex, and $\mathrm{T}$ wave) was calculated as millivolts $(\mathrm{mV})$ while the height of each small square was considered as $0.01 \mathrm{mV}$. The total length of the small squares was also measured for cardiac segments \& intervals (P-R segment, ST segment, Q-T interval, P-R interval) while the length of each small square was considered .04 seconds (s). It should be noted that ECG indices were measured using lead 2 in 12-lead ECG.

Data Analysis

After conducting the appropriate tests to confirm the normality of dependent variables' distribution (Kolmogorov-Smirnov test) and the homogenize of variances (Levene test), between-group differences were determined by independent samples $t$ test for physiological characteristics at baseline and by multivariate analysis of variance (MANOVA) test in a general linear model for dependent variables of this study. Post hoc test was also used for significant difference of MANOVA test at baseline after 12 weeks exercise intervention, and after 5 months detraining. To determine the difference at baseline, after 12 weeks exercise intervention, and after 5 months detraining, values for each group were assessed by repeated measures test and the post hoc pairwise comparisons test was used for its significant difference. The statistical software program SPSS (SPSS Inc., Chicago IL, version 23) for Windows was used for data analysis. The statistical significance was considered at a $P \leq 0.05$.

\section{Results}

There was no significant difference between the E and $\mathrm{C}$ groups regarding baseline individual characteristics
(Table 1).

The results of this study showed that after 12 weeks of W-WJMIAEP-R, ECG indices were not significantly different, except for P-R interval $(P=0.020)$. The between-groups results of this study exhibited that after 5 months detraining, ECG indices were not of a significant difference, except for P-R segment and S-T interval, which were significantly different $(P=0.042$ and $P=0.001$, respectively, Table 2 and Table 3 ).

The results of inter-groups in this study showed that there was no difference in any of the ECG indices after 12 weeks exercise intervention in the E group and the $\mathrm{C}$ group $(P>0.05)$. After 5 months detraining, intergroups results exhibited that $\mathrm{P}-\mathrm{R}$ segment $(P=0.012)$ in the E group and QRS complex $(P=0.011), \mathrm{P}-\mathrm{R}$ interval $(P=0.044)$, and $\mathrm{S}-\mathrm{T}$ interval $(P=0.022)$ in the $\mathrm{C}$ group were significantly changed (Table 4 and Table 5 ).

\section{Discussion}

The purpose of this study was to investigate the effects of 12 weeks of W-WJMIEP-R and 5 months detraining on ECG indices in post-menopausal women. The results of this study demonstrated that after 12 weeks of W-WJMIAEP-R, P-R interval increased significantly in between-groups, whereas other ECG indices were not significantly different. The results of between-groups showed that the P-R segment and S-T interval decreased significantly after 5 months detraining, whereas other dependent variables were not of a significant difference. The results of the current study were consistent with the results of some previous studies ${ }^{13,14}$ and were inconsistent with others. ${ }^{15,16}$

Nayara et $\mathrm{al}^{13}$ reported that the heart rate after 12 weeks of walking at 55\%-65\% reserve heart rate in elderly women was of no significant changes, which results of this study were consistent with the findings of the current study. Also, Amirazodi et al ${ }^{14}$ reported that eight weeks of low-intensity aerobic exercise did not change heart rate in elderly men. Our results were consistent with those studies with similar aspects to our protocol

Table 1. Comparison of the Homogeneity of Sedentary Post-Menopausal Women at Baseline in the Exercise and Control groups

\begin{tabular}{|c|c|c|c|c|c|c|}
\hline Variables & E Group $(n=12)$ & C Group $(n=12)$ & Levene Test & PValue $^{\mathrm{a}}$ & Independent $\mathrm{t}$ test & $P_{\text {Value }}$ b \\
\hline Age $(y)$ & $53.36 \pm 3.98$ & $53.00 \pm 3.26$ & 1.395 & 0.254 & -0.223 & 0.826 \\
\hline Height (cm) & $157.45 \pm 45$ & $158.40 \pm 5.42$ & 0.001 & 0.997 & 0.923 & 0.369 \\
\hline Weight (kg) & $73.20 \pm 10.25$ & $76.10 \pm 15.95$ & 0.171 & 0.685 & -0.343 & 0.736 \\
\hline Body mass index $\left(\mathrm{kg} / \mathrm{m}^{2}\right)$ & $29.67 \pm 5.15$ & $30.29 \pm 6.58$ & 1.465 & 0.243 & -0.554 & 0.587 \\
\hline Systolic BP (mm Hg) & $130.00 \pm 23.16$ & $116.80 \pm 17.66$ & 3.459 & 0.080 & 0.716 & 0.484 \\
\hline Diastolic BP (mm Hg) & $77.63 \pm 16.53$ & $79.00 \pm 13.82$ & 4.768 & 0.052 & 0.763 & 0.456 \\
\hline Heart rate (beats/min) & $78.90 \pm 8.27$ & $71.33 \pm 8.50$ & 1.123 & 0.304 & -1.379 & 0.186 \\
\hline $\mathrm{VO}_{2} \max (\mathrm{mL} / \mathrm{kg} / \mathrm{min})$ & $39.05 \pm 2.25$ & $39.71 \pm 1.38$ & 0.334 & 0.579 & 1.011 & 0.342 \\
\hline $17 \beta$-estradiol (ng/ $\mu \mathrm{L})$ & $27.32 \pm 11.04$ & $41.17 \pm 6.83$ & 1.230 & 0.292 & 2.221 & 0.053 \\
\hline Progesterone $(\mathrm{ng} / \mu \mathrm{L})$ & $0.20 \pm 0.10$ & $0.35 \pm 0.19$ & 2.720 & 0.130 & 1.770 & 0.106 \\
\hline
\end{tabular}

$\mathrm{E}=$ Exercise group; $\mathrm{C}=$ Control group; $\mathrm{VO}_{2} \max =$ Maximal oxygen uptake. Values are shown as mean $\pm \mathrm{SD}$;

a Significant level of Levene test; ${ }^{\text {b }} P \leq 0.05$, significant difference between-groups at baseline values. 
Table 2. Comparison of the Means of EEG Indices Between-Groups at Baseline, After 12 Weeks Exercise Intervention, and After Five Months Detraining in Post-menopausal Women

\begin{tabular}{|c|c|c|c|c|c|c|c|c|c|}
\hline \multirow[b]{2}{*}{ Variables } & \multicolumn{3}{|l|}{ E Group } & \multicolumn{3}{|l|}{ C Group } & \multirow[b]{2}{*}{$\mathbf{F}$} & \multirow[b]{2}{*}{$P$ Value } & \multirow[b]{2}{*}{$\mathrm{Eta}^{\mathrm{b}}$} \\
\hline & $\begin{array}{l}\text { Baseline } \\
(n=12)\end{array}$ & $\begin{array}{l}\text { After } 12 \text { Weeks } \\
\text { Exercise }(n=12)\end{array}$ & $\begin{array}{l}\text { E Group After } 5 \\
\text { Months Detraining } \\
(n=12)\end{array}$ & $\begin{array}{l}\text { Baseline } \\
(n=12)\end{array}$ & $\begin{array}{l}\text { After } 12 \text { Weeks } \\
\text { Exercise }(n=12)\end{array}$ & $\begin{array}{l}\text { C Group } \\
\text { After } 5 \text { Months } \\
\text { Detraining }(n=12)\end{array}$ & & & \\
\hline Heart rate (bt/min) & $80.81 \pm 10.94$ & $78.54 \pm 6.81$ & $78.45 \pm 6.72$ & $76.72 \pm 10.70$ & $76.27 \pm 9.23$ & $77.72 \pm 9.30$ & 2.358 & 0.123 & 0.208 \\
\hline P wave $(\mathrm{mV})$ & $0.11 \pm 0.03$ & $0.21 \pm 0.23$ & $0.12 \pm 0.03$ & $0.13 \pm 0.38$ & $0.22 \pm 0.23$ & $0.19 \pm 0.25$ & 1.470 & 0.258 & 0.147 \\
\hline QRS (mV) & $0.54 \pm 0.27$ & $0.58 \pm 0.15$ & $0.54 \pm 0.18$ & $0.67 \pm 0.12$ & $0.59 \pm 0.13$ & $0.60 \pm 0.14$ & 0.432 & 0.656 & 0.048 \\
\hline T wave $(\mathrm{mV})$ & $0.16 \pm 0.10$ & $0.13 \pm 0.05$ & $0.13 \pm 0.05$ & $0.10 \pm 0.03$ & $0.11 \pm 0.03$ & $0.11 \pm 0.03$ & 0.448 & 0.647 & 0.050 \\
\hline P-R interval (ms) & $0.11 \pm 0.20$ & $0.12 \pm 0.02$ & $0.11 \pm 0.01$ & $0.12 \pm 0.04$ & $0.12 \pm 0.04$ & $0.13 \pm 0.04$ & 5.866 & $0.011^{\mathrm{a}}$ & 0.409 \\
\hline P-R segment (ms) & $0.09 \pm 0.02$ & $0.09 \pm 0.02$ & $0.07 \pm 0.01$ & $0.09 \pm 0.03$ & $0.09 \pm 0.04$ & $0.09 \pm 0.03$ & 4.178 & 0.033 & 0.330 \\
\hline S-T interval (ms) & $0.15 \pm 0.06$ & $0.18 \pm 0.03$ & $0.15 \pm 0.03$ & $0.15 \pm 0.03$ & $0.19 \pm 0.04$ & $0.22 \pm 0.03$ & 7.886 & $0.004^{a}$ & 0.481 \\
\hline Q-T interval (ms) & $0.18 \pm 0.06$ & $0.22 \pm 0.04$ & $0.21 \pm 0.06$ & $0.20 \pm 0.04$ & $0.21 \pm 0.05$ & $0.23 \pm 0.04$ & 0.513 & 0.608 & 0.057 \\
\hline
\end{tabular}

Values are shown as mean $\pm \mathrm{SD} ; \mathrm{F}=\mathrm{MANOVA}$ test; ${ }^{\mathrm{a}} \mathrm{P} \leq 0.05$, a significant difference between-groups at baseline, after 12 weeks exercise intervention, and after 5 months detraining values; ${ }^{\text {b }}$ Partial Eta squared or estimates of effect size.

Table 3. Post Hoc Results of Multivariate Analysis of Group Effects on Dependent Variables

\begin{tabular}{|c|c|c|c|c|c|c|}
\hline Dependent Variables & Sum of Squares & $d f$ & Mean Square & $\mathbf{F}$ & $P$ Value & $\mathbf{E t a}^{\mathrm{b}}$ \\
\hline P-R interval after 12 weeks exercise & 0.001 & 1 & 0.001 & 6.526 & $0.020^{\mathrm{a}}$ & 0.266 \\
\hline P-R interval after 5 months detraining & 0.001 & 1 & 0.001 & 1.971 & 0.177 & 0.099 \\
\hline P-R segment after 12 weeks exercise & 0 & 1 & 0 & 0.997 & 0.331 & 0.052 \\
\hline P-R segment after 5 months detraining & 0.001 & 1 & 0.001 & 4.768 & $0.042^{\mathrm{a}}$ & 0.209 \\
\hline S-T interval after 12 weeks exercise & 0.001 & 1 & 0.001 & 0.781 & 0.388 & 0.042 \\
\hline S-T interval after 5 months detraining & 0.017 & 1 & 0.017 & 16.611 & $0.001^{\mathrm{a}}$ & 0.480 \\
\hline
\end{tabular}

${ }^{a} P \leq 0.05$, a significant difference between-groups; ${ }^{\text {b }}$ Partial Eta squared or estimates of effect size.

Table 4. Comparison of the Mean Changes Inter-groups at Baseline, After 12 Weeks Exercise Intervention, and After 5 Months Detraining in Exercise and Control Groups

\begin{tabular}{|c|c|c|c|c|c|c|}
\hline Variables & Baseline $(n=12)$ & $\begin{array}{l}\text { After } 12 \text { Weeks } \\
\text { Exercise }(n=12)\end{array}$ & $\begin{array}{l}\text { After } 5 \text { Months } \\
\text { Detraining }(n=12)\end{array}$ & $d f$ & $\begin{array}{l}\text { F Repeated } \\
\text { Measures }\end{array}$ & $P$ Value \\
\hline \multicolumn{7}{|c|}{ Exercise Group } \\
\hline Heart rate (beat/min) & $80.81 \pm 10.94$ & $78.54 \pm 6.81$ & $78.45 \pm 6.72$ & 11 & 0.818 & 0.472 \\
\hline P wave $(\mathrm{mV})$ & $0.11 \pm 0.03$ & $0.21 \pm 0.23$ & $0.12 \pm 0.03$ & 11 & 1.320 & 0.314 \\
\hline QRS complex (mV) & $0.54 \pm 0.27$ & $0.58 \pm 0.15$ & $0.54 \pm 0.18$ & 11 & 0.996 & 0.407 \\
\hline T wave $(\mathrm{mV})$ & $0.16 \pm 0.10$ & $0.13 \pm 0.05$ & $0.13 \pm 0.05$ & 11 & 0.314 & 0.738 \\
\hline P-R interval (ms) & $0.11 \pm 0.20$ & $0.12 \pm 0.02$ & $0.11 \pm 0.01$ & 11 & 3.171 & 0.091 \\
\hline P-R segment (ms) & $0.09 \pm 0.02$ & $0.09 \pm 0.02$ & $0.07 \pm 0.01$ & 11 & 4.748 & $0.039^{\mathrm{a}}$ \\
\hline S-T interval (ms) & $0.15 \pm 0.06$ & $0.18 \pm 0.03$ & $0.15 \pm 0.03$ & 11 & 1.453 & 0.284 \\
\hline Q-T interval (ms) & $0.18 \pm 0.06$ & $0.22 \pm 0.04$ & $0.21 \pm 0.06$ & 11 & 3.091 & 0.095 \\
\hline \multicolumn{7}{|c|}{ Control Group } \\
\hline Heart rate (beat/min) & $76.72 \pm 10.70$ & $76.27 \pm 9.23$ & $77.72 \pm 9.30$ & 11 & 2.614 & 0.127 \\
\hline P wave $(\mathrm{mV})$ & $0.13 \pm 0.38$ & $0.22 \pm 0.23$ & $0.19 \pm 0.25$ & 11 & 1.810 & 0.224 \\
\hline QRS complex (mV) & $0.67 \pm 0.12$ & $0.59 \pm 0.13$ & $0.60 \pm 0.14$ & 11 & 5.127 & $0.037^{a}$ \\
\hline T wave $(\mathrm{mV})$ & $0.10 \pm 0.03$ & $0.11 \pm 0.03$ & $0.11 \pm 0.03$ & 11 & 0.190 & 0.831 \\
\hline P-R interval (ms) & $0.12 \pm 0.04$ & $0.12 \pm 0.04$ & $0.13 \pm 0.04$ & 11 & 5.076 & 0.038 \\
\hline P-R segment (ms) & $0.09 \pm 0.03$ & $0.09 \pm 0.04$ & $0.09 \pm 0.03$ & 11 & 0.382 & 0.695 \\
\hline S-T interval (ms) & $0.15 \pm 0.03$ & $0.19 \pm 0.04$ & $0.22 \pm 0.03$ & 11 & 5.002 & $0.039^{a}$ \\
\hline Q-T interval (ms) & $0.20 \pm 0.04$ & $0.21 \pm 0.05$ & $0.23 \pm 0.04$ & 11 & 3.061 & 0.104 \\
\hline
\end{tabular}

Values are shown as mean $\pm \mathrm{SD}$; ${ }^{P} \leq 0.05$, a significant difference inter-groups. 
Table 5. Post Hoc Results of Repeated Measures of Group Effects by Pairwise Comparisons on Dependent Variables

\begin{tabular}{|c|c|c|c|c|c|}
\hline Variables & Group & & Mean Difference & Standard Error & $P$ Value \\
\hline \multirow{3}{*}{ P-R segment (E group) } & Baseline & After 12 weeks exercise & -0.005 & 0.006 & 0.291 \\
\hline & Baseline & After 5 months detraining & 0.014 & 0.005 & $0.016^{\mathrm{a}}$ \\
\hline & After 12 weeks exercise & After 5 months detraining & 0.019 & 0.007 & $0.020^{\mathrm{a}}$ \\
\hline \multirow{3}{*}{$\begin{array}{l}\text { QRS complex (C } \\
\text { group) }\end{array}$} & Baseline & After 12 weeks exercise & 0.074 & 0.045 & 0.135 \\
\hline & Baseline & After 5 months detraining & 0.064 & 0.020 & $0.011^{\mathrm{a}}$ \\
\hline & After 12 weeks exercise & After 5 months detraining & -0.010 & 0.033 & 0.767 \\
\hline \multirow{3}{*}{ P-R interval (C group) } & Baseline & After 12 weeks exercise & 0.004 & 0.003 & 0.269 \\
\hline & Baseline & After 5 months detraining & -0.008 & 0.007 & 0.300 \\
\hline & After 12 weeks exercise & After 5 months detraining & -0.012 & 0.005 & $0.044^{\mathrm{a}}$ \\
\hline \multirow{3}{*}{ S-T interval (C group) } & Baseline & After 12 weeks exercise & -0.0 .24 & 0.021 & 0.282 \\
\hline & Baseline & After 5 months detraining & -0.045 & 0.016 & $0.022^{\mathrm{a}}$ \\
\hline & After 12 weeks exercise & After 5 months detraining & -0.021 & 0.012 & 0.123 \\
\hline
\end{tabular}

$\mathrm{E}=$ Exercise group; $\mathrm{C}=\mathrm{Control}$ group; ${ }^{\mathrm{a}} \mathrm{P} \leq 0.05$, significant difference inter-groups in different stages of evaluation.

including Nayara et $\mathrm{al}^{13}$ (12 weeks of aerobic exercise of 55\%-65\% maximal heart rate of reserve, three sessions per week, and 40-50 min per training session in postmenopausal women), Ebrahim et $\mathrm{al}^{17}$ (similar subjects of post-menopausal women and aerobic exercise), and Malandish et $\mathrm{al}^{10}$ (the same exercise protocol of 12 weeks of aerobic exercise). In contrast, the difference in the longterm aerobic training protocol of 6-months in Moazemi and Jamali ${ }^{16}$ study and 24 -week aerobic exercise of $65 \%$ maximal heart rate in Tartibian et $\mathrm{al}^{15}$ study, as well as the age and gender differences of subjects in other studies, ${ }^{18}$ may be of possible inconsistency reasons with the results of our study.

The results of studies indicate that the $\mathrm{P}$ wave size is related to the modality and intensity of exercise. ${ }^{19,20}$ Also, recent studies have reported that cardiac muscle has vitamin $\mathrm{D}$ receptors and it is possible that the decrease of vitamin $\mathrm{D}$ receptors in the aging process and/or menopause has sarcopenia effects on cardiac function and consequently a direct role for vitamin $\mathrm{D}$ has been shown in the de-regulation of cardiac contractility. ${ }^{21,22}$ Since the serum levels of vitamin D play an important role in the depolarization and repolarization of myocardium, as well as changes in depolarization and repolarization of myocardium, ${ }^{8}$ and its changes, affect cardiac output (Q) and stroke volume (SV), it is possible that the absence of changes in the atrial depolarization and/or $\mathrm{P}$ wave during 12 weeks of W-WJMIAEP-R in post-menopausal women can be related to the positive adaptations in cardiovascular system. Also, the neurohumoral regulation of cardiovascular function controls heart rate, BP, Q, and regional blood flow. ${ }^{23}$ In other words, the unchanged heart rate after 12-week exercise intervention in between-groups can be related to other factors in chronic deactivation of the neurohumoral systems such as atrial natriuretic peptide, brain natriuretic peptide, angiotensin II, aldosterone, and other neurohumoral factors in atrial remodeling. ${ }^{23,24}$ However, there are various mechanisms for the significant changes of heart rate, including central command, arterial baroreceptors, cardiopulmonary receptors, peripheral and arterial chemoreceptors, decreased cardiac sympathetic activity, and ventilation. ${ }^{6}$ The cardiac vagal modulation can be also a reason for heart rate variability (HRV), as increased cardiac vagal activity has been reported during aerobic exercise. ${ }^{6}$ Also, heart rate and other electrophysiological indices can be influenced by genetic factors as well. ${ }^{25}$

As mentioned previously, the QRS complex represents ventricular depolarization. ${ }^{6}$ In other words, increased size and wall thickness of ventricular cavities caused by exercise lead to the QRS voltage for left ventricular hypertrophy, which is associated with increasing end-diastolic diameter. ${ }^{6}$ It is likely that 12 -week of W-WJMIAEP-R has no effect on volume overload even with increased venous return and $\mathrm{Q}$, as the ventricles in this condition are not strong enough to sustain forceful contractions.

The results of this study showed a significant difference in the P-R interval and/or atrial depolarization and delay in the impulse in the AV node during 12 weeks exercise intervention in the between-groups analysis. It seems that the P-R interval prolongation is associated with the atrial aging process. ${ }^{26}$ It has been reported that the sympathetic-parasympathetic balance and as well as the AV conduction properties are involved in the $\mathrm{P}-\mathrm{R}$ interval determination. ${ }^{27}$ In other words, it is likely that W-WJMIAEP-R intervention affects sympatheticparasympathetic balance, resulting in atrial adaptations. Also, the activity of sinus and AV nodes are strongly regulated by the autonomic nervous system (ANS), and therefore positive adaptations resulting from 12 weeks of exercise in this study can be involved. Also, it is possible that aerobic exercise in sedentary post-menopausal women increases maximal exercise performance reflecting an increase in peak oxygen uptake. ${ }^{6}$ Furthermore, aerobic exercise is associated with increased cardiovascular system capacity, and thereby decreased resting heart rate 
and increased ventricular volume. ${ }^{6}$ In other words, aerobic exercise-induced cardiovascular system adaptations can be accompanied by a better quality of life and decreased cardiovascular diseases in sedentary post-menopausal women. ${ }^{3,9}$ In addition, moderate-intensity aerobic exercise provides changes in the heart that contribute to the greater peak Q and aerobic capacity. Changes in cardiac dimensions and blood volume play the primary role in enhancing SV, and hence Q. ${ }^{6}$ Furthermore, cardiovascular adaptations to aerobic exercise allow the heart to maintain a given submaximal work level at a lower heart rate, and thus with less strain on the heart. It is likely that aerobic exercise-induced cardiac dimensions adaptations results in left ventricular hypertrophy increased left ventricular end-diastolic diameter, and increased ventricular wall thickness. $^{6}$ In conclusion, aerobic exercise inducedadaptations and atrial depolarization-related biomarkers are very limited necessitating more studies.

As mentioned above, the results of 5 months detraining in our study showed that among the dependent variables of 12-lead ECG, only the P-R segment, and S-T interval were significantly different in between-groups. Most studies related to detraining in older people aged 50-70 years have reported the functional physical fitness. ${ }^{10,29}$ Cardiovascular biomarkers responses, decreased strength, and aerobic fitness in some studies of detraining have also revealed. ${ }^{28}$ Other studies have demonstrated that increased muscle strength and some of the cardiovascular serum levels during exercise training are maintained after detraining for either 4 weeks, ${ }^{10} 12$ weeks, ${ }^{30} 24$ weeks, ${ }^{31} 27$ weeks, ${ }^{32} 31$ weeks, ${ }^{33}$ and 15 months ${ }^{29}$ in older adults. In other words, some studies have reported that physiological and morphological adaptations are decreased even after short detraining periods, ${ }^{28,34}$ whereas others have demonstrated that not only physiological adaptations related to cardiovascular system are maintained, ${ }^{29}$ but also some of these adaptations can be increased after detraining periods in older people. ${ }^{30-33}$

In this regard, the results of studies revealed that the age, gender differences, fitness level, aerobic capacity, exercise protocol types, and duration of the detraining period can be involved in ECG alternations in older adults. ${ }^{28-33}$

$\mathrm{PR}$ interval prolongation is a marker of atrial structural and electrical remodeling. ${ }^{26}$ Many electrophysiological studies have reported that the atrial electrical properties are strongly altered in left ventricular systolic dysfunction. ${ }^{26,35}$ Electrophysiological studies have also demonstrated that increased conduction times and refractories in atria are related to the aging process. ${ }^{26,36,37}$ Furthermore, the P-R segment prolongation is an independent risk factor for cardiovascular disease. ${ }^{26}$ According to the P-R segment changes, positive adaptations resulting from 12-week of W-WJMIEP-R as a non-pharmacological factor are likely to be involved in prevention of atrial aging such as decreased atrial electrical conductions, decreased P-R segment, and as well as some of the cellular mechanisms involved in the prevention of cardiovascular aging process, especially atrial aging. ${ }^{26}$ In other words, the results of this study showed that a long period of physical inactivation does not affect the positive ECG adaptations of 12 weeks of W-WJMIAEP-R.

Furthermore, reduced ventricular depolarization and ventricular wall thickness are associated with an increase in ventricular repolarization or T wave time. ${ }^{6}$ In other words, insufficient levels of Vitamin D in post-menopausal women are associated with increased ventricular repolarization. So, it is possible that ECG alternations observed in control group be related to the aging process in post-menopausal women. Also, the reduction of significant ventricular depolarization and end-diastolic diameter decreased $\mathrm{Q}$ and venous return due to decreased volume overload results in abnormal contractions of the ventricular wall, ${ }^{6}$ elevated ventricular repolarization, and reduced ventricular depolarization. In this regard, Nakagawa et $\mathrm{al}^{38}$ reported that Q-T interval is affected by natural events such as menopause, and probably these variations are in parallel to changes in serum levels of sex hormones, such as estrogen. ${ }^{39}$ The exact impact of hormones, especially sex hormones, on arrhythmic mechanisms and cardiac conduction system are unclear. ${ }^{39}$

Recently, the results of studies have shown that increased reactive oxygen species (ROS) due to elevated oxidative stress levels increase the cardiac inflammatory indices such as C-reactive protein (CRP) and the increase in age-related apoptosis. ${ }^{40}$ Consequently, it is possible that atrial negative regulation leads to a pre-excitation syndrome or a block in the AV node in post-menopause period. ${ }^{6}$ Also, studies have exhibited that impulse delay in the AV node and atrial depolarization is increased with the aging process. ${ }^{26}$ It has been reported that sympatheticparasympathetic imbalance impairs the impulse delay in the AV node and atrial depolarization. ${ }^{27}$ In other words, it is possible that aging process impair the sympatheticparasympathetic balance and this event leads to the atrial depolarization in line with the pre-excitation syndrome and/or block in the $\mathrm{AV}$ node in post-menopausal women. ${ }^{30}$

On the other hand, it is possible that positive regulation of renin-angiotensin-aldosterone system caused by positive adaptations after 12 weeks of exercise intervention leads to the atrial structural and electrical remodeling, ${ }^{40}$ resulting in increased atrial depolarization. Furthermore, it is likely that increased estrogen receptors in cardiac cells by aerobic exercise lead to a decrease in CRP, resulting in a positive regulation in the atrial depolarization. ${ }^{40}$

\section{Strengths and Limitations}

The effects of 12-week of aerobic exercise along with a five-month long detraining period are the strengths of this study. In contrast, the low number of subjects is the main limitations of this study. 


\section{Conclusion}

The results of this study indicated that 12 weeks of walking \& jogging aerobic exercise with $65 \%-70 \%$ maximal heart rate increased the P-R interval in sedentary postmenopausal women. The P-R segment and S-T interval decreased significantly after five months detraining period. In other words, it is possible that 12 weeks aerobic exercise induced-ECG positive adaptations such as decrease P-R segment and S-T interval are maintained even after a long detraining period and consequently prevents the increase in atrial aging process during the long detraining period in post-menopausal women.

\section{Ethical Approval}

All stages of this study were approved by the Ethics Committee of Allameh Tabataba'i University, Iran (Code: $\mathrm{T} / \mathrm{D} / 108)$.

\section{Competing Interests}

Authors declare that they have no competing interests.

\section{Acknowledgment}

This study was supported by a grant from Allameh Tabataba'i University, Tehran, Iran. The authors are grateful to the subjects who participated in this study.

\section{References}

1. Emerson KG, Gay J. Physical Activity and Cardiovascular Disease Among Older Adults: The Case of Race and Ethnicity. J Aging Phys Act. 2017;25(4):505-509. doi:10.1123/japa.2016-0012

2. Tartibian B, Afsar Gharehbag R, Malandish A, Sheikhlou Z. Correlation between blood pressure and vitamin $\mathrm{D}$, parathyroid hormone, calcium, and phosphorus in sedentary postmenopausal women. Tehran Univ Med J. 2016;74(8):554-561.

3. Tartibian B, Botelho Teixeira AM, Baghaiee B. Moderate intensity exercise is associated with decreased angiotensinconverting enzyme, increased beta2-adrenergic receptor gene expression, and lower blood pressure in middle-aged men. J Aging Phys Act. 2015;23(2):212-220. doi:10.1123/ japa.2013-0136

4. Shahsavari S, Nazari F, Karimyar Jahromi M, Sadeghi M. Epidemiologic study of hospitalized cardiovascular patients in Jahrom hospitals in 2012- 2013. Cardiovasc Nurs J. 2013;2(2):14-21.

5. Krenc Z. Relationship Between Adaptive Morphological and Electrophysiological Remodeling of the Left Ventricle in Young Athletes After an 8-Month Period of Sports Training. Pediatr Exerc Sci. 2016;28(1):71-76. doi:10.1123/ pes.2015-0106

6. Tartibian B, Malandish A. Advanced cardiovascular exercise physiology. 1st ed. Urmia: Urmia University Publishers; 2012:117-158.

7. McNamara DA, Ng J, Ilkhanoff L, Schaechter A, Goldberger JJ, Kadish AH. Associations of Sex Hormones With Surface Electrocardiogram J Point Amplitude in Healthy Volunteers. Am J Cardiol. 2017;119(11):1877-
1882. doi:10.1016/j.amjcard.2017.02.035

8. Zhang Y, Post WS, Dalal D, et al. Serum 25-hydroxyvitamin D, calcium, phosphorus, and electrocardiographic QT interval duration: findings from NHANES III and ARIC. J Clin Endocrinol Metab. 2011;96(6):1873-1882. doi:10.1210/jc.2010-2969

9. Azadpour N, Tartibian B, Kosar SN. Effects of aerobic exercise training on ACE and ADRB2 gene expression, plasma angiotensin II level, and flow-mediated dilation: a study on obese postmenopausal women with prehypertension. Menopause. 2017;24(3):269-277. doi:10.1097/gme.0000000000000762

10. Malandish A, Tartibian B, Rahmati Yamchi M. Effect of 12 Weeks of Moderate-Intensity Aerobic Training on Bone Density and Serum Indices of Bone in Sedentary Postmenopausal Women. Sport Physio. 2016;8(32):67-84. doi:10.22089/spj.2016.862

11. Bull FC, Maslin TS, Armstrong T. Global physical activity questionnaire (GPAQ): nine country reliability and validity study. J Phys Act Health. 2009;6(6):790-804.

12. Faul F, Erdfelder E, Lang AG, Buchner A. G*Power 3: a flexible statistical power analysis program for the social, behavioral, and biomedical sciences. Behav Res Methods. 2007;39(2):175-191.

13. Braz NF, Carneiro MV, Oliveira-Ferreira F, et al. Influence of aerobic training on cardiovascular and metabolic parameters in ederly hypertensive women. Int J Prev Med. 2012;3(9):652-659.

14. Amirazodi M, Daryanoosh F, Babaee Begi MA, Koshki Jahromi M, Mehrabi A. Effect of aerobic exercise on plasma vasoactive intestinal peptide, blood pressure and heart rate of elderly healthy persons and coronary artery patients. Tehran Univ Med J. 2013;71(3):185-193.

15. Tartibian B, Hajizadeh Maleki B, Kanaley J, Sadeghi K. Long-term aerobic exercise and omega-3 supplementation modulate osteoporosis through inflammatory mechanisms in post-menopausal women: a randomized, repeated measures study. Nutr Metab (Lond). 2011;8:71. doi:10.1186/1743-7075-8-71

16. Moazzami M, Sadat Jamali F. The effect of 6-months aerobic exercises on Bone-specific alkaline phosphatase and parathyroid hormone in obese inactive woman. J Sport Biomotor Sci. 2013;5(10):71-79.

17. Ebrahim KH, Ramezanpor MR, Rezaei Sahraei A. Effect of Eight Weeks of Aerobic and Progressive Exercises on Changes of Estrogen Hormone and Effective Factors on Bone Mass in Menopaused Sedentary Women. Iran J Endocrinol Metab. 2010;12(4):401-408.

18. Genovesi S, Zaccaria D, Rossi E, Valsecchi MG, Stella A, Stramba-Badiale M. Effects of exercise training on heart rate and QT interval in healthy young individuals: are there gender differences? Europace. 2007;9(1):55-60. doi:10.1093/europace/eul145

19. Brugger N, Krause R, Carlen F, et al. Effect of lifetime endurance training on left atrial mechanical function and on the risk of atrial fibrillation. Int J Cardiol. 2014;170(3):419-425. doi:10.1016/j.ijcard.2013.11.032

20. Wilhelm M, Roten L, Tanner H, Schmid JP, Wilhelm I, Saner H. Long-term cardiac remodeling and arrhythmias in nonelite marathon runners. Am J Cardiol. 2012;110(1):129- 
135. doi:10.1016/j.amjcard.2012.02.058

21. Meems LM, Cannon MV, Mahmud H, et al. The vitamin $\mathrm{D}$ receptor activator paricalcitol prevents fibrosis and diastolic dysfunction in a murine model of pressure overload. J Steroid Biochem Mol Biol. 2012;132(3-5):282289. doi:10.1016/j.jsbmb.2012.06.004

22. Meems LM, van der Harst P, van Gilst WH, de Boer RA. Vitamin D biology in heart failure: molecular mechanisms and systematic review. Curr Drug Targets. 2011;12(1):2941.

23. Blume GG, McLeod CJ, Barnes ME, et al. Left atrial function: physiology, assessment, and clinical implications. Eur J Echocardiogr. 2011;12(6):421-430. doi:10.1093/ ejechocard/jeq175

24. Casaclang-Verzosa G, Gersh BJ, Tsang TS. Structural and functional remodeling of the left atrium: clinical and therapeutic implications for atrial fibrillation. J Am Coll Cardiol. 2008;51(1):1-11. doi:10.1016/j.jacc.2007.09.026

25. Orini M, Tinker A, Munroe PB, Lambiase PD. Long-term intra-individual reproducibility of heart rate dynamics during exercise and recovery in the UK Biobank cohort. PLoS One. 2017;12(9):e0183732. doi:10.1371/journal. pone. 0183732

26. MagnaniJW, Wang N, Nelson KP, et al. Electrocardiographic PR interval and adverse outcomes in older adults: the Health, Aging, and Body Composition study. Circ Arrhythm Electrophysiol. 2013;6(1):84-90. doi:10.1161/ circep.112.975342

27. Cabasson A, Meste O, Blain G, Bermon S. Quantifying the PR interval pattern during dynamic exercise and recovery. IEEE Trans Biomed Eng. 2009;56(11):2675-2683. doi:10.1109/tbme.2009.2028694

28. Mahdiabadi J, Mahdiabadi MA, Kazemi T. The effect of aerobic continuous training and detraining on left ventricular structure and function in male students. Phys Educ Stud. 2017;21(2):61-65. doi:10.15561/20755279.2017.0202

29. Lobo A, Carvalho J, Santos P. Effects of Training and Detraining on Physical Fitness, Physical Activity Patterns, Cardiovascular Variables, and HRQoL after 3 HealthPromotion Interventions in Institutionalized Elders. Int J Family Med. 2010;2010:486097. doi:10.1155/2010/486097

30. de Souza Padilha C, Silva Ribeiro A, da Silva DRP, et al. Effect of resistance training and detraining on the oxidative stress in obese older women. Rev Bras Cineantropom
Desempenho Hum. 2015;17(5):517-526. doi:10.5007/19800037.2015v17n5p517

31. Toraman NF. Short term and long term detraining: is there any difference between young-old and old people? Br J Sports Med. 2005;39(8):561-564. doi:10.1136/ bjsm.2004.015420

32. Schlicht J, Camaione DN, Owen SV. Effect of intense strength training on standing balance, walking speed, and sit-to-stand performance in older adults. J Gerontol A Biol Sci Med Sci. 2001;56(5):M281-286.

33. Hakkinen K, Alen M, Kallinen M, Newton RU, Kraemer WJ. Neuromuscular adaptation during prolonged strength training, detraining and re-strength-training in middleaged and elderly people. Eur J Appl Physiol. 2000;83(1):5162. doi: $10.1007 / \mathrm{s} 004210000248$

34. Delshad M, Ghanbarian A, Mehrabi Y, Sarvghadi F, Ebrahim K. Effect of Strength Training and Short-term Detraining on Muscle Mass in Women Aged Over 50 Years Old. Int J Prev Med. 2013;4(12):1386-1394.

35. Sanders P, Morton JB, Davidson NC, et al. Electrical remodeling of the atria in congestive heart failure: electrophysiological and electroanatomic mapping in humans. Circulation. 2003;108(12):1461-1468. doi:10.1161/01.cir.0000090688.49283.67

36. Kojodjojo P, Kanagaratnam P, Markides V, Davies DW, Peters N. Age-related changes in human left and right atrial conduction. J Cardiovasc Electrophysiol. 2006;17(2):120127. doi:10.1111/j.1540-8167.2005.00293.x

37. Kistler PM, Sanders P, Fynn SP, et al. Electrophysiologic and electroanatomic changes in the human atrium associated with age. J Am Coll Cardiol. 2004;44(1):109116. doi:10.1016/j.jacc.2004.03.044

38. Nakagawa $M$, Ooie $T$, Takahashi $N$, et al. Influence of menstrual cycle on QT interval dynamics. Pacing Clin Electrophysiol. 2006;29(6):607-613. doi:10.1111/j.15408159.2006.00407.x

39. Dogan U, Dogan NU, Basarir AO, et al. P-wave parameters and cardiac repolarization indices: does menopausal status matter? J Cardiol. 2012;60(4):333-337. doi:10.1016/j. jjcc.2012.04.001

40. Zhang Z, Yang Y, Ng CY, et al. Meta-analysis of Vitamin D Deficiency and Risk of Atrial Fibrillation. Clin Cardiol. 2016;39(9):537-543. doi:10.1002/clc.22563 